\title{
Impact of Advances in Mobile Technology on Higher Education in Developing Countries
}

\author{
Nazir Ahmad Suhail \\ Kampala University, Kampala \\ Uganda
}

\begin{abstract}
Last few decades witnessed vast advancements in mobile wireless communication systems. Mobile wireless technologies have been developing gradually, giving birth to various different techniques that consist of a number of generations ranging from $1 \mathrm{G}$ to $5 \mathrm{G}$. This paper investigates the radical and innovative changes in mobile telecommunication networks. Literature survey research approach was used. The impact of radical changes in telecommunication networks is highlighted. Research found that impact of technology advancements and their usage in higher education in emerging economies are both Positive and Negative. However, positive impacts are enormous and negative impacts are minimal comparatively. The study also found that such advancements in mobile communication networks have changed the definition of distance learning, from print media to digital and an interactive education.
\end{abstract}

\section{Keywords}

Smartphones, evolution of mobile phones, technology impact on higher education, developing countries.

\section{INTRODUCTION}

In the latest strings of technological advancements and innovations of $21^{\mathrm{st}}$ Century, smartphones are the leading devices taking the front end. Smartphone is a part of an advanced category of mobile phones that runs on a powerful complete operating system in a manner similar to a computer, which offers innovative computing abilities and connectivity options [1]. The evolutionary course of convergence of wireless communications and computing technologies have led to rapid advances and developments in mobile phones that brought about social changes in many areas including financial institutions, health, business, and education. As a result, the smartphone emerged as a leading technology of the aforementioned convergence. Sony Ericsson, Palm Treo, Blackberry, Nokia T-Mobile Sidekick, Torq, Motorola Q, ETen, HP iPaq, Apple iPads, iPod, iPhone, and Samsung Galaxy Tabs are some of the examples of smartphones/tablets [2].

The smartphone functionalities include: instant messaging, calling, sending and receiving text messages, surfing the Web, display photos, play games, play videos, navigation, built-in camera, audio/video playback and recording, among others [3]. The smartphones use one of the following powerful operating systems: Windows, Symbian (or its derivatives), Blackberry, Android, and iOS. Smartphones are redefining the academic environment in developing countries and are the ready tool for faster access to all type of knowledge. By using iPhone, iPad, other smartphones and tablets, required information can be easily accessed by students and lecturers [4].

Due to its ubiquitous nature and provision of variety of services, the smartphones are playing the role of universal mobile terminal at the institutions of higher learning in developing countries and developed world [5]. In the recent years the use of smartphone for academic purpose at higher education has increased many folds among students to fulfill their knowledge thrust. It is expected that advanced mobile phone technology will be globally ubiquitous by 2020 such that 70 percent people of the entire population will be smartphone users. The smartphone features such as audio, video, Internet communication, information retrieval, and ecommerce makes the device as one of the necessities for many people.

Smartphones have become an integral part of education system in developing countries [6]. The usage of mobile phones in learning process enhances students' learning experience in many different ways. According to [7], mobile phone technologies impact on learning process includes portability, collaboration, and motivation. The portability nature of mobile phones enables learners to carry the technology anywhere inside or outside the campus, home and field trips to obtain or retrieve course information to improve a wide variety of learning settings.

Students' interaction through social media networks such as Twitter and Facebook accessed on smartphones help them to share their knowledge and information by forming groups, which could result in successful collaborative learning. Finally, students at institutions of higher learning use mobile phones as learning tool and appear to be more motivated and engaged in learning process as it also increases group participation in activities done during learning in class([7], cited in [8]). However, research on the influence of mobile phones on Higher Education in developing countries did not attract much attention by researchers [8]. Therefore, this paper explores the impact of technological advancements on higher education in developing countries to fill the knowledge gap.

\section{GROWTH IN MOBILE TECHNOLOGY}

There have been vast advancements in handheld wireless communication systems, in the last few decades that resulted into innovations in mobile wireless generations from $1 \mathrm{G}$ to $5 \mathrm{G}$.

From the perspective of functionality, these generations mainly differ in four aspects; radio access, data rates, bandwidth, and switching schemes [9].

The first Generation (1G) of mobile phones began in 1980 , with only one functionality of voice communication service [10] and was based on Advanced Mobile Phone System (AMPS) technology. The $1 \mathrm{G}$ cellular systems were mainly analog systems, had a bandwidth ranging from 10 to $30 \mathrm{KHz}$, data rates were approximately $10 \mathrm{Kbps}$, Radio access scheme used was Frequency Division Multiple Access (FDMA), and switching was all circuit to support voice services [9]. 1G introduced the technologies such as Push to Talk (PTT), 
Mobile Telephone System (MTS), Advanced Mobile Telephone System (AMTS), and Improved Mobile Telephone Service (IMTS) [11]. Moreover, various different standards of IG were used in different countries. United Kingdom used Total Access Communications System (TACS), United States used Advanced Mobile Phone System (AMPS), and Nordic Mobile Telephone (NMT) was used by Nordic countries, Eastern Europe and Russia [12].

Gavas [13] pointed out that $1 \mathrm{G}$ had low capacity coupled with no security of voice calls, unreliable handoff, and poor voice links. Hence, there was need for improved transmission quality, higher system capacity, better system coverage, better and more services, security, and better spectral efficiency that paved the way towards second generation cellular systems [9].

The second generation of Mobile phones was 2G that was based on Global System for Mobile communications (GSM), a standard developed by the European Telecommunications Standards Institute (ETSI) meant to describe the protocols for $2 \mathrm{G}$ digital cellular networks. The main features of $2 \mathrm{G}$ technology [14] included: digital signals instead of analogue for voice transmission with long life mobile batteries as the digital signals consume less battery power, speed up to 64 kbps, improved voice clarity and reduced noise in the line, short message service (SMS), picture messages, and Multimedia message service (MMS). The other service provided by $2 \mathrm{G}$ was e-mail and worldwide wireless web (WWW) access [15].

$2 \mathrm{G}$ was followed by Third Generation (3G) which is superseding all previous generations, including First Generation (1G) and Second generation (2G). The success factors and user acceptance of the third generation mobile network and its services have been investigated by many researchers. $3 \mathrm{G}$ provided some distinct enhancements over $1 \mathrm{G}$ and $2 \mathrm{G}$ such as Web and WAP browsing at higher speeds, Video-conferencing, Enhanced audio and video streaming, Higher data speed and IPTV (TV through the Internet) support[16], Sending/Receiving large email messages, High speed web, More security, Video conferencing, High speed downloads, 3D gaming, Large capacities and Broadband capabilities [11]. In addition, $3 \mathrm{G}$ is cheaper for service providers and is extremely faster. However, $3 \mathrm{G}$ technology also has some disadvantages such that download speeds can sometimes be slower than expected due to variation in the signal strength depending upon the device being used.

$4 \mathrm{G}$ is the fourth generation of mobile technology, which is fundamentally the expansion in the $3 \mathrm{G}$ that removed the limitations and problems of $3 \mathrm{G}$ system and is 10 times faster than 3G. Long Term Evolution (LTE) is considered as $4 \mathrm{G}$ technology. In 4G mobile systems different access technologies such as WLAN, WMAN and cellular are combined on a common platform and they interoperate to offer different services in different radio environments [17]. The main features of $4 \mathrm{G}$ [18] include: the capability to interface with wire line backbone network which can transmit various multimedia and data across the world, frequency band ranges from 2 to $8 \mathrm{GHz}$, data rate is more than $20 \mathrm{Mbps}$, bandwidth is $5-20 \mathrm{MHz}$ same as of $3 \mathrm{G}$, uses the multi-carrierCDMA or OFDM(TDMA), switching technique is packet switching, has ability to quickly download files over a wireless network, provides extremely high voice quality, can easily access Internet and social Networks, has ability of streaming media, and facilitates video calling services. Author [11] added some more features in $4 \mathrm{G}$ such as high security, provides any kind of service at any time as per user requirements anywhere, and offers multimedia expanded services. However, $4 \mathrm{G}$ is also associated with some disadvantages that include more battery usage, hard to implement the system, and needed complicated hardware whereby customer is forced to buy new device.

$5 \mathrm{G}$ is the fifth generation of the standards of telecommunication technology. For $5 \mathrm{G}$ research is still in progress [18]. 5G will be complete wireless communication with no limitations. Some of the main features of 5G [11] are expected to be:

- $\quad$ Supportable to Wireless World Wide Web

- $\quad$ High speed

- High capacity

- Provision of large broadcasting of data

- Enhanced clarity in TV programs

- Enhanced data transmission rate

- Mobile phones with large memory

\section{IMPACT OF TECHNOLOGY ADVANCEMENTS ON HIGHER EDUCATION}

Smartphone usage in higher education has increased many folds as the new technology introduced another means for accessing knowledge. The impacts of technology advancements and usage on higher education in emerging economies are both Positive and Negative.

\subsection{Positive Impacts}

The Institution of Higher learning in developing countries might unarguably be the most prevalent beneficiary of the advancements in mobile technologies. In developing countries services rendered by smart phone can play integral role in education, they are not mere additional devices. The smartphones enable students to access to larger amount of learning material. Internet is one of the main challenges some of developing countries facing whereby smartphone can easily handle that issue.

In developing countries smartphone tool can help students to achieve or perform well by learning faster outside the lecture room, accessing the Internet and easy retrieval of required academic material. Using smartphones lecturers can also keep themselves aware of any recent developments and global trend required in their teaching and research needs. The major areas where smartphones have made tremendous impact on the universities in developing countries in education are easy and fast internet access, high speed browsing, saving time and money going to internet café or campus computer laboratory, easy access to teaching and learning content which is enough relief to the lecturers and students as the smart devices are at their disposal to save them from stress in accessing the required information which were previously difficult [2].

Research [19] indicates that a larger percentage of students at universities in emerging economies have latest smartphones and have expertise in using their services such as GPRS for location, Whatsapp, Facebook for networking, taking pictures, creating albums, checking email, Internet surfing and using for other programs. Moreover, these smartphones with various functionalities make easier for students to use them for distance learning, where they can collaborate with fellow class mates and lecturers. 
Smartphone is a perfect tool for distance learning. The recent advancements in wireless communication systems are transforming the definition of distance learning from print media to "digital and an interactive education" ([20], cited in [21]). Author [20] maintains that mobile communication technology bridges the gap between distance learners and instructors as the technology has the potential to deliver learning content to anywhere, any time as per needs, and enabling a two-way interaction between participants.

\subsection{Negative Impacts}

Using smartphones students can send and receive text messages, interact on social media, use e-mail services, play online games, and even watch TV programmes, which are sources of distraction for themselves, and for other students. Using smartphone students can cheat by accessing information online during examinations. The study conducted by [22] concluded that students in the institutions of higher learning in developing countries are moving fast with technology advancements, especially in mobile phones and waste much of their precious time in non-academic activities such as attending to message notifications on WhatsApp, Twitter, Instagram, Facebook and chatting each other, taking selfie pictures to share with one another in social networks about the status. Researchers also noted that smartphones hinder students from performing better in their studies.

Sir [2] asserts that in developing countries students face some other challenges that include Non-availability of experts to repairs on campus, operational difficulties or poor usage skills, high cost of data subscription from Internet Service Providers (ISPs), irregular/unstable power supply for regular charging of battery on campus and other barriers facing the use of smartphone. Smart phones are high-tech digital devices, with many functionalities that require user to have some knowledge to use them, otherwise this will amount to frustration and underutilization of the devices for academic purposes. Research shows that in addition, Technological, intellectual, access and lack of awareness were some of the other possible barriers of smartphones usage [4] by students and academic staff in developing countries.

\section{CONCLUSION}

In this this paper literature was drawn from various resources on modern advancements in mobile technology. Evolution of mobile telecommunication network from $1 \mathrm{G}$ to $5 \mathrm{G}$ is highlighted. The paper also discussed the impact of these technological advancements on higher education in developing countries. Both positive and negative impacts are clearly explained. However, it is important to educate students in Institutions of Higher learning in developing countries on how to use smartphones smartly to enhance their academic career. At the same time, they should focus on how to avoid smartly the misuse of innovative technology. The study concludes that positive impacts of technology advancements are tremendous and negative impacts are minor on Higher Education Institutions in developing countries [23].

\section{REFERENCES}

[1] Alfawareh, H.M. and Jusoh, S. 2014. Smartphones usage among university students: Najran University case,International Journal of Academic Research, Vol.6, No.2,321- 326 .

[2] Sir, E.V.E. 2015. "Impact of Smartphones Tablets on the Information Seeking Behavior of Medical Staff of NigerDelta University Bayelsa State - Nigeria",
LibraryPhilosophy and Practice (e-journal) 1288, South Africa(online).

[3] Sarwar, M. and Soomro,T. R. 2013. Impact of Smartphone's on Society, European Journal of ScientificResearch, Vol. 98, No. 2, March, 2013, 216226.

[4] Boruff, J.T. and Storie, D. 2014. Mobile devices in medicine: a survey of how medical students, residents, and faculty use smartphones and other mobile devices to findinformation, Journal of Medical Library Association,Vol.102, No.1, 22-30.

[5] Alhajri, R. 2016. Prospects and Challenges of MobileLearning Implementation: A Case Study, J Inform Tech Softw Eng 6: 189. doi: 10.4172/21657866.1000189

[6] Srivastava, L. 2005. Mobile Phones and Evolution of Social Behavior, Behavior and Information Technology, Vol. 24, Issue2, 2005.

[7] Barker, A., Krull, G. and Mallinson, B. 2006. A Proposed Theoretical Model for M-Learning Adoption in Developing Countries. Department of InformationSystems Rhodes University.

[8] Jumoke,S., Oloruntoba, S. A. and Blessing, O. 2015. Analysis of Mobile Phone Impact on Student AcademicPerformance in Tertiary Institution, International Journalof Emerging Technology and Advanced Engineering,Vol.5, Issue 1, January, 2015.

[9] Mousa, A.M. 2012. Prospective of Fifth GenerationMobile Communications, International Journal of Next-Generation Networks (IJNGN) Vol.4, No.3, September, 2012.

[10] Suhail .N.A. 2017. Assessing Mobile LearningReadiness in Kampala University, Uganda, International Journal of Computer Applications Vol.170, No.2, 30-34, July, 2017.

[11] Vora, L. J. 2015. Evolution of mobile generation technology: $1 \mathrm{~g}$ to $5 \mathrm{~g}$ and review of upcoming wirelesstechnology $5 \mathrm{~g}$, International Journal of Modern Trends in Engineering and Research (IJMTER), Vol. 2, Issue 10,October, 2015.

[12] Gruber, H. and Koutroumpis, P. 2010. Mobile Communications: Diffusion facts and prospects,Communications and Strategies 77, 2010, 133145

[13] Gawas, A.U. 2015. An Overview on Evolution of Mobile Wireless Communication Networks: 1G-6G,International Journal on Recent and innovation trends incomputing and communication (JRITCC), Vol. 3,Issue 5, May, 2015.

[14] Bulbul, A.Al-M.,Biswas, S., Hossain, M.B., Biswas,S. 2017. Past, Present and Future of Mobile WirelessCommunication,IOSR Journal of Electronics and Communication Engineering (IOSR-JECE,Vol. 12, Issue5,Ver. I (Sep.-Oct, 2017), 55-58.

[15] Chung, J. M., Park, K., Won, T. and Choi, S. 2010New protocols for future wireless systems", 53rd IEEE International Midwest Symposium on Circuits andSystems, 2010. 
[16] Bhalla, M. R. and Bhalla, A. V. 2010. "Generations ofmobile wireless technology: A survey", InternationalJournal of Computer Applications, Vol.5, No. 4, 2010.

[17] Ray, S. K. 2006. Fourth Generation (4g) Networks:Roadmap- Migration to the Future, IETE Technical Review, Vol 23, No 4, July-August 2006, 253265.

[18] Lakshitha, V., Reddy,K.V.R., Jayanth,G., JagadeeshRaju, C.J. and Manikandan, K. 2018. 3G, 4G AND 5G:AComparative Study, International Research Journal of Engineering and Technology (IRJET), Vol. 5, Issue 3,Mar, 2018

[19] Tuncay, N. 2016. Smartphones as Tools for DistanceEducation, Journal of Educational and InstructionalStudies in the world, Vol.6, Issus 2, May 2016.
[20] Hiple, D. and Fleming, S. (n.d.). Models For Distance Education in Critical Languages, University of Hawai' $i$ at MÅnoa.(Retrieved on 10th February, 2007). http://nflrc.hawaii.edu/networks/tr25/TR25-1.pdf

[21] Kuswani, G.S.N. 2008. Mobile Phones As Support For Distance Learning, In the Proceedings of the IADISInternational Conference e-Learning 2008.

[22] Kibona ,L., Rugina, J.M. 2015. Review on the Impactof Smartphones on Academic performance of Students in Higher Learning Institutions in Tanzania, A Case ofRuaha Catholic University, Iringa , Journal of Multidisciplinary Engineering Science and Technology (JMEST), Vol. 2 Issue 4, April, 2015.

[23] Gowthami, S.,VenkataKrishnaKumar, S. 2016. Impact of Smartphone: A pilot study on positive and negative effects, International Journal of Scientific Engineering and Applied Science (IJSEAS),Vol.2, Issue3, March, 2016. 